\title{
VASA Is a Specific Marker for Both Normal and Malignant Human Germ Cells
}

\author{
Anne-Marie Zeeman, Hans Stoop, Marjan Boter, Ad J. M. Gillis, Diego H. Castrillon, \\ J. Wolter Oosterhuis, and Leendert H. J. Looijenga \\ Department of Pathology/Laboratory for Experimental Patho-Oncology (A-MZ, HS, MB, AJMG, JWO, LHJL), \\ University Hospital of Rotterdam/Daniel, Josephine Nefkens Institute, Erasmus University Rotterdam, The Nether- \\ lands; and Women's and Perinatal Pathology Division, Department of Pathology (DHC), Brigham and Women's \\ Hospital and Harvard Medical School, Boston, Massachusetts
}

SUMMARY: VASA is so far the only known gene in mammals whose expression is specific for the germ cell lineage. We investigated the presence of VASA mRNA and protein in a series of germ cell tumors of different histologic subtypes and anatomic location, as well as in nongerm cell tumors such as testicular lymphomas and Leydig cell tumors. We detected VASA mRNA (by quantitative RT-PCR) and protein (by immunohistochemical staining) in normal spermatogenesis, seminoma (both classic and spermatocytic), carcinoma in situ (the precursor of classic seminoma and nonseminoma), dysgerminoma, and gonadoblastoma. VASA immunostaining was relatively weak in seminomas and dysgerminomas compared with spermatocytic seminomas, despite similar mRNA levels, suggesting that VASA is regulated in part by post-transcriptional mechanisms. A higher staining intensity compared with the invasive counterparts was observed in the precursor lesions (ie, carcinoma in situ and gonadoblastoma). No VASA mRNA or protein was detectable in nonseminomatous germ cell tumors (such as embryonal carcinoma, teratoma, and yolk sac tumor) and derived cell lines, or nongerm cell tumors such as lymphoma or Leydig cell tumor. These results provide direct evidence that some germ cell tumors retain germ cell characteristics, whereas other tumors of germ cell origin result from differentiation and loss of germ cell identity. Furthermore, these findings suggest that VASA is likely to serve as a useful and highly specific biomarker for germ cell tumors, particularly classic and spermatocytic seminoma/dysgerminoma, including their precursor stages. (Lab Invest 2002, 82:159-166).

$T$ he evolutionary highly conserved VASA genes are specifically expressed in the germ cell lineage, both in vertebrates and invertebrates (for review, see Raz, 2000). Members of this family have been identified in C. elegans, Drosophila, Xenopus, zebrafish, chicken, rainbow trout, rat, and mouse. The Drosophila vasa gene encodes a DEAD-box protein with ATP-dependent RNA-helicase activity (Hay et al, 1988; Lasko and Ashburner 1988). The helicase activity is required for the translation of at least two mRNAs involved in germ cell migration and development, ie, nanos (Forbes and Lehmann 1998; Gavis et al, 1996; Kobayashi et al, 1996) and gurken (Gonzalez-Reyes et al, 1995; Neuman-Silberberg and Schupbach 1993; Roth et al, 1995; Styhler et al, 1998; Tomancak et al, 1998). VASA is present in the developing oocyte and is part of the germ plasm, a poorly understood ribonucleoprotein complex crucial for germ cell determination. In Drosophila, vasa is essential for the formation

Received September 24, 2001

This research was supported by the Dutch Cancer Society (KWF-DDHK 99-1968).

Address reprint requests to: Dr. L. H. J. Looijenga, Department of Pathology/Laboratory for Experimental Patho-Oncology, University Hospital Rotterdam/Daniel, Josephine Nefkens Institute, Erasmus University Rotterdam, Building Be, Room 430b, PO Box 1738, 3000 DR Rotterdam, The Netherlands. E-mail: looijenga@leph.azr.nl of germ cells. The mouse homolog of VASA, known as mvh (mouse Vasa homolog) was recently identified. Its expression is also restricted to the germ cell lineage (Tanaka et al, 2000). Although male knock-out mice for mvh form primordial germ cells, they subsequently develop testicular atrophy because of abnormal proliferation and colonization of the primordial germ cells, as well as death of zygotene spermatocytes, and are infertile.

The human VASA gene was recently cloned. VASA mRNA and protein are abundantly and specifically expressed in germ cells in both sexes throughout development. In contrast to mice, where the protein is induced after the primordial germ cells reach the genital ridge, immunohistochemistry demonstrated that in humans, the VASA protein is already present in migrating primordial germ cells. During normal spermatogenesis, VASA staining is relatively weak to intermediate in spermatogonia, strong in spermatocytes/spermatids, and absent in spermatozoa (Castrillon et al, 2000). In the human adult testis, two biologically and clinically distinct types of germ cellderived tumors are recognized. These are distinguished by epidemiologic characteristics, histology, clinical behavior, and chromosomal constitution (Looijenga and Oosterhuis, 1999 for review). The first comprises the seminomas and nonseminomas, here referred to as testicular germ cell tumors of adoles- 
cents and adults (TGCT), and represent the most common neoplasms in young Caucasian males (Adami et al, 1994; Pottern et al, 1998; Swerdlow 1993). Although it is most likely that the initiating event in the development of TGCT occurs during embryonic development (Jørgensen et al, 1995; Møller, 1989, for review), affecting a primordial germ cell, leading to carcinoma in situ (CIS) (Skakkebæk 1972), also known as intratubular germ cell neoplasm (ITGCN), the tumors only become clinically manifest after puberty. CIS cells, like primordial germ cells, are characterized by a high glycogen content (Mostofi and Sesterhenn 1998), membranous staining for the stem cell factor receptor C-KIT (Rajpert-De Meyts and Skakkebæk 1994), and germ cell/placental alkaline phosphatase (GCAP/PLAP) (Roelofs et al, 1999, for review). CIS cells can progress to seminoma, an invasive tumor in which the malignant cells still show, like CIS cells, morphologic and immunohistochemical characteristics of primordial germ cells. CIS cells can also progress to nonseminomas, tumors of germ cell origin that have lost their primordial germ cell characteristics, and recapitulate embryonic development (Looijenga et al, 1997, for review). Nonseminomatous germ cell tumors exhibit morphologic and immunohistochemical evidence of differentiation into various somatic (teratoma) and extraembryonic lineages (yolk sac tumor and choriocarcinoma). In addition, embryonal carcinoma can be found. Each of these histologic subtypes can be found in a pure form or in combinations with other types (Mostofi and Sesterhenn 1998). Seminomas and nonseminomas can also be found in the ovary and dysgenetic gonads (Oosterhuis et al, 1993, for review). The ovarian counterpart of seminoma is known as dysgerminoma and is histologically indistinguishable from seminoma. The CIS-like lesion that arises in dysgenetic gonads is referred to as gonadoblastoma (Scully 1970; Jørgensen et al, 1997, for review).

The second category of testicular tumors derived from the germ cell lineage are the spermatocytic seminomas. These tumors develop usually at a relatively advanced age, rarely metastasize, and are assumed to be derived from a later developmental stage of spermatogenesis (spermatocytes) than the precursor cells of TGCT (Burke and Mostofi, 1993; Eble, 1994; Muller et al, 1987; Romanenko and Persidskii, 1983; Rosai et al, 1969; Stoop et al, 2001; Talerman, 1974, 1980; Talerman et al, 1984). Their different pathogenesis from TGCT is also illustrated by the lack of glycogen (Mostofi and Sesterhenn, 1998), C-KIT, and GCAP/PLAP (Dekker et al, 1992), their positive staining for SSX, SCP1, and XPA (Stoop et al, 2001), as well as their unique chromosomal constitution (Looijenga et al, 1994; Rosenberg et al, 1998).

We investigated whether tumors derived from the germ cell lineage (ie, gonadoblastoma/CIS, dysgerminoma/seminomas, nonseminomas, and spermatocytic seminomas) can be identified specifically on the basis of the presence of VASA mRNA and protein.

\section{Results}

\section{Immunohistochemistry for VASA and GCAP/PLAP}

To study the presence of VASA protein in different human tumors, we performed immunohistochemistry on formalin-fixed paraffin-embedded tissue sections using previously described polyclonal antibodies (Castrillon et al, 2000). The tested samples include gonadoblastoma $(n=5)$, dysgerminoma $(n=5)$, normal testicular parenchyma $(n=5)$ (containing spermatogenesis), primary testicular lymphomas $(n=$ $3)$, Leydig cell tumors $(n=3)$, testicular parenchyma containing different amounts of CIS-cells and Sertoli only tubules $(n=14)$, seminomas $(n=13)$, nonseminomas $(n=12)$, and spermatocytic seminomas $(n=$ 4). The results are summarized in Table 1. Representative examples are shown in Figure 1.

Relatively weak staining for VASA was found in spermatogonia, whereas stronger staining was detected in later developmental stages. Spermatozoa were negative (Fig. 1A). These results are in accordance with earlier data (Castrillon et al, 2000). CIS/ seminoma and gonadoblastoma/dysgerminoma cells were identified by their positive staining for GCAP/ PLAP (see Fig. 1, B and C). Double immunohistochemistry for GCAP/PLAP and VASA demonstrated that all of these malignant cells are positive for VASA. Although the overall intensity of the staining was in the same order as found for spermatogonia, the preinvasive stage (ie, gonadoblastoma and CIS), showed a more intense staining compared with their invasive counterparts (ie, dysgerminoma and seminoma; see

Table 1. Summary of the Results of Immunohistochemistry for VASA on Germ Cell Tumors of Different Histology and Anatomical Localization, as well as Nongerm Cell Tumors and Normal Testicular Parenchyma

\begin{tabular}{lcc}
\hline \multicolumn{1}{c}{ Histology } & Cases tested & Staining $^{a}$ \\
\hline Testicular parenchyma & 19 & - \\
$\quad$ Leydig cells & & - \\
$\quad$ Sertoli cells & - \\
$\quad$ Stromal cells & ++ \\
$\quad$ Spermatogonia & & +++ \\
$\quad$ Spermatocytes & & +++ \\
$\quad$ Spermatids & 3 & - \\
$\quad$ Spermatozoa & 3 & - \\
Leydig cell tumor & 5 & - \\
Testicular lymphoma & 5 & ++ \\
Gonadoblastoma & 14 & ++ \\
Dysgerminoma & 13 & + \\
Carcinoma in situ & 12 & - \\
Seminoma & 4 & +++ \\
Nonseminoma & \\
Spermatocytic seminoma & & + \\
\hline${ }^{a}$ Staining intensity:,- negative;,+ weak;,++ intermediate;,+++ \\
strong. \\
${ }^{b}$ The nonseminomas included multiple independent elements of embryonal \\
carcinoma, teratoma, and yolk sac tumor.
\end{tabular}



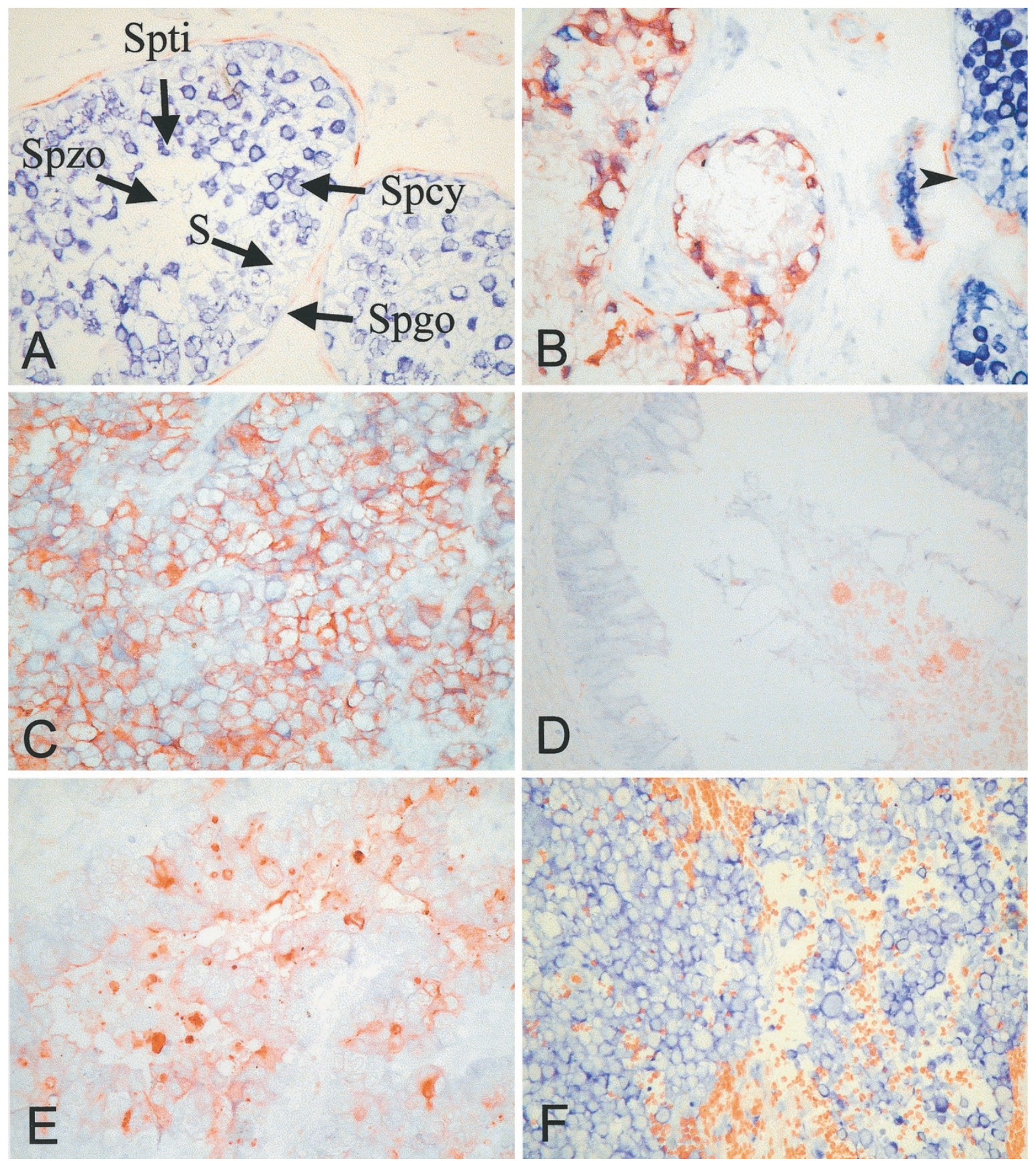

Figure 1.

Immunohistochemical detection of VASA (blue) and GCAP/PLAP (red) in several testicular tissues (original magnification, $\times 200$ ). A, VASA staining is clearly visible in normal testis, with a weak intensity in spermatogonia (Spgo), a strong intensity in spermatocytes till spermatids (Spcy/Spti), and no staining in spermatozoa (Spzo) and Sertoli cells $(S)$; B, Testicular parenchyma without carcinoma in situ $(C / S)$ cells are negative for GCAP/PLAP. However, CIS cells are positive for GCAP/PLAP as well as VASA. Spermatogonia of the normal tubules (arrowhead in upper right) show VASA staining intensity similar to CIS tubules. C. Classic seminomas are overall weakly VASA positive and show strong GCAP/PLAP staining. D, Teratoma and E, embryonal carcinoma are negative for VASA, although some positive cells for GCAP/PLAP are identified in the latter. F, Spermatocytic seminomas are strongly positive for VASA and negative for GCAP/PLAP. Red blood cells appear orange.

Fig. 1, B and C). A similar staining intensity was observed with single immunohistochemical labeling (data not shown). None of the nonseminomas showed staining for VASA (see Fig. 1, D and E). As described previously (Roelofs et al, 1999), some of the embryonal carcinoma cells still contain GCAP/PLAP. However, these cells were negative for VASA (see Fig. 1E), which demonstrates that the presence of GCAP/PLAP is not coupled to the presence of VASA. This is also demonstrated by the lack of GCAP/PLAP in spermatocytic seminomas, whereas these tumors were strongly positive for VASA (see Fig. 1F). The intensity of staining in spermatocytic seminomas appears to correspond to the pattern in normal spermatogenesis, 
A

Lymph.

2021222324

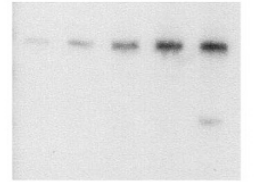

Nonsem.

2021222324

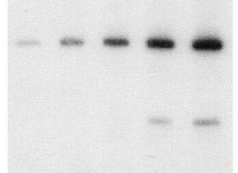

Test. paren.

2021222324

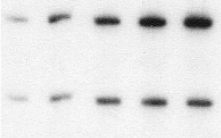

Class. sem.

$202122 \quad 2324 \quad$ Amplification cycles

$-\cdots$ HPRT

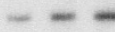

VASA

B

2021222324 Amplification cycles

HPRT

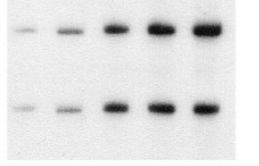

VASA

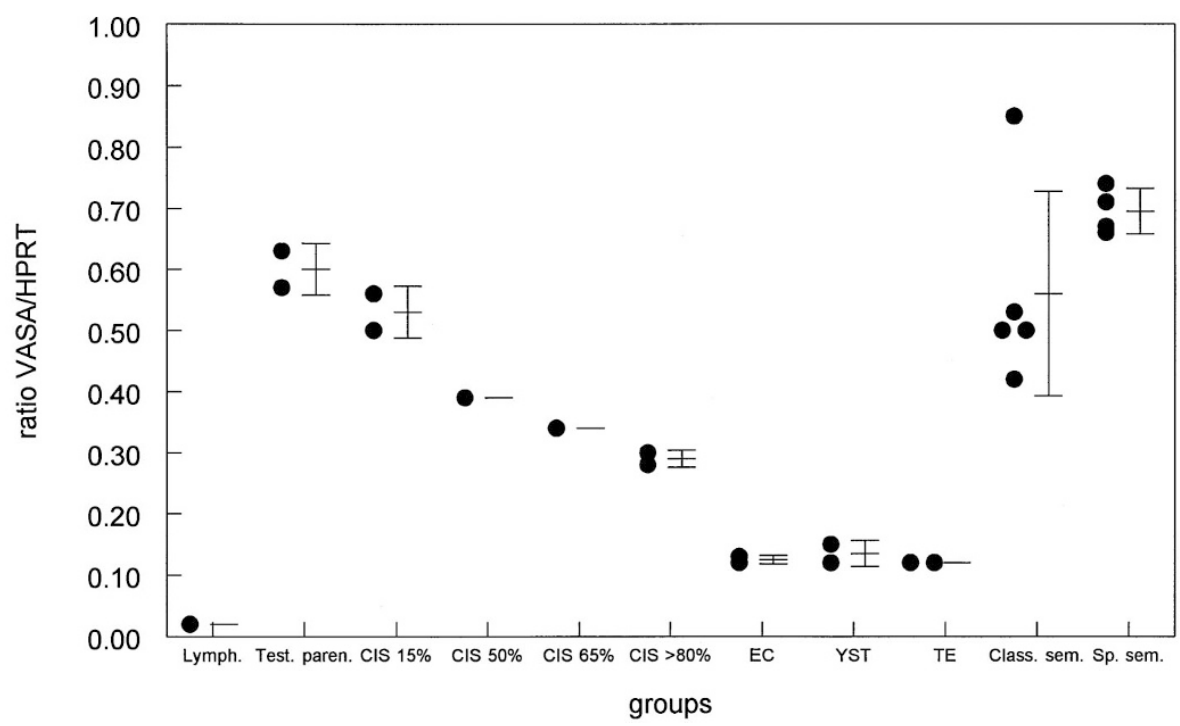

Figure 2.

Relative VASA transcript levels in several testicular tissues as determined by semiquantitative RT-PCR. A, Representative autoradiograms of semiquantitative RT-PCR on several tissues (Lymph.: Iymphocytes; Test. paren.: normal testicular parenchyma; Class. sem.: classic seminoma; Nonsem.: nonseminoma; Sperm. sem.: spermatocytic seminoma). The number of amplification cycles are depicted above the autoradiograms. Lymphocytes and nonseminomas show a lower transcript level of VASA compared with classic seminoma and spermatocytic seminomas. B, Summary of the results of the semiquantitative RT-PCR. Increasing amounts of CIS-cells (from $15 \%$ to more than $80 \%$ of the seminiferous tubules) as indicated in the graph, correlate with decreasing VASA/HPRT ratios. Classic seminomas (Class. Sem.) do not show significant differences in VASA mRNA levels compared with normal testicular parenchyma (Test. paren.), nor do spermatocytic seminomas (Sp. + sem.). Nonseminomas of all histologic subtypes (EC: embryonal carcinoma, $Y S$ : yolk sac tumor, TE: teratoma,) show a reduced transcript level of VASA. The results of the individual samples and the mean and standard deviation of the histologic groups are indicated.

where staining is strongest in spermatocytes (see Fig. $1 \mathrm{~A})$.

\section{Quantification of VASA Transcript Levels}

To study whether the different levels of VASA protein in the different types of germ cell-derived tumors are due to transcriptional or post-transcriptional regulation, we determined the VASA mRNA levels using semiquantitative RT-PCR. The VASA-transcript levels were compared with the level of HPRT, a housekeep- ing gene with a relatively constant level of expression. To exclude DNA contamination, the VASA primers were designed to span several introns (see "Materials and Methods"). Representative examples are shown in Figure 2A, and the results are summarized in Figure 2B. Lymphocytes were used as negative control, and normal testicular parenchyma (containing spermatogenesis) as positive control. As expected, lymphocytes showed extremely low levels of VASA expression, even after 24 amplification cycles, whereas a relatively high level (0.6 times the level of HPRT) was 
detected in testicular parenchyma with spermatogenesis. The level of VASA expression was inversely proportional to the percentage of CIS-containing seminiferous tubules; in samples with more than $80 \%$ positive tubules, the VASA/HPRT ratio was reduced by a factor of two. It is important to note that with increasing percentage of CIS-containing seminiferous tubules, the percentage of seminiferous tubules with normal spermatogenesis is reduced.

Classic seminoma samples showed VASA expression levels in the same range as in samples of normal testicular parenchyma (mean VASA/HPRT ratio, 0.56; standard deviation, 0.16). In contrast, a significantly lower level of expression $(p<0.00013$, Student's $t$ test) was found in all histologic types of nonseminomas (mean ratio, 0.13; standard deviation, 0.012). In fact, the level of expression was reduced by a factor of 4.7 compared with normal testis. In addition, no or extremely low levels of VASA expression were observed in four nonseminoma-derived cell lines (data not shown). These expression levels likely account for the difference in protein level as detected by immunohistochemistry in nonseminomas. Although spermatocytic seminomas showed a stronger staining intensity for VASA than classic seminoma (see above), only a slightly higher level of expression was found (mean VASA/HPRT ratio, 0.69; standard deviation, 0.037) (see Fig. 2, A and B).

\section{Discussion}

In the human adult testis, on the basis of biologic and clinical data, two categories of germ cell-derived tumors are distinguished: (1) seminomas and nonseminomas, here referred to as TGCT, and (2) spermatocytic seminomas (Looijenga and Oosterhuis, 1999, for review). The TGCT originate from CIS (Skakkebæk, 1972), also referred to as intratubular germ cell neoplasia (ITGCN), the premalignant counterpart of primordial germ cells. Although classic seminoma cells are morphologically and immunohistochemically highly similar to CIS, nonseminomas such as teratoma, yolk sac tumor, and choriocarcinoma reflect differentiation to other lineages with concomitant loss of their germ cell-like characteristics (Mostofi and Sesterhenn 1998, for review). In contrast, spermatocytic seminomas still exhibit similarities to cells belonging to the germ cell lineage (Burke and Mostofi, 1993; Cummings et al, 1994; Eble, 1994). They have a different etiology and clinical behavior from TGCT (Burke and Mostofi, 1993; Dekker et al, 1992; Looijenga et al, 1994; Rosenberg et al, 1998; Stoop et al, 2001). Available data suggest that spermatocytic seminomas originate from a later developmental stage of the germ cell than TGCT, most likely spermatocytes (Burke and Mostofi, 1993; Dekker et al, 1992; Eble, 1994; Muller et al, 1987; Romanenko and Persidskii, 1983; Rosai et al, 1969; Talerman, 1974, 1980; Talerman et al, 1984; ). However, we recently found indications that the cell of origin of spermatocytic seminoma might be at an earlier stage of development than spermatocytes. This cell is capable of further matura- tion and partial meiosis (Looijenga et al, 1994; Rosenberg et al, 1998; Stoop et al, 2001).

The germ cell origin of CIS/classic seminoma and spermatocytic seminomas is supported by our findings on the specific expression of VASA mRNA and protein in these tumors. This also is true for gonadoblastoma/dysgerminoma, which are the CIS and classic seminoma counterparts in dysgenetic gonads and ovary. Although classic seminomas and spermatocytic seminomas showed a comparable level of VASA mRNA, about 0.6 times the level of HPRT, more intense immunohistochemical staining was found in spermatocytic seminomas than in classic seminomas. This indicates that post-transcriptional mechanisms regulate VASA protein levels. Indeed, it is known that in Drosophila oocytes, vasa is subjected to posttranslational modification (Ghabrial and Schupbach 1999). The intensity of staining in the spermatocytic seminomas was comparable to that found in more differentiated germ cells during spermatogenesis (ie, from spermatocytes till spermatids; Castrillon et al, 2000 , and this paper). This supports the model that spermatocytic seminoma cells are spermatocyte-like or are capable of developing to this stage of maturation. In addition, the lower staining intensity observed in CIS/seminoma-and gonadoblastoma/dysgerminoma cells-supports the notion that these tumor cells originate from an earlier germ cell precursor, and are less capable of undergoing maturation in the germ cell lineage. In contrast, all nonseminomas, independent of the histology, as well as cell lines derived from them, have lost VASA expression, at both the mRNA and protein level. This is therefore due to transcriptional down-regulation on differentiation and loss of the germ cell phenotype. The mechanisms involved are unknown, and regulators of VASA expression remain to be identified.

It is of interest that the actual protein level of $m v h$ (the mouse homolog of VASA) in primordial germ cells is regulated by interaction with gonadal somatic cells (Toyooka et al, 2000). In this context, the lower staining intensity in the dysgerminomas/classic seminomas compared with their preinvasive stage (ie, gonadoblastoma/CIS) is of interest. The composition of the intratubular microenvironment of the precursor cells is remarkably different from that of the invasive tumors; in contrast to the invasive tumor cells, both gonadoblastoma and CIS cells are still interacting with their physiologic supportive cells (granulosa/Sertoli cells). Thus, differences in cell-cell interactions may account for differing protein levels we observed, similar to observations made in the mouse. It is, however, from our results, not possible to draw any conclusion about possible differences in levels of transcription of VASA between preinvasive and invasive cells. The reason is that in parenchyma with $80 \% \mathrm{CIS}$, only a few of the cells are CIS cells (Mosselman et al, 1996). The reduced level of VASA transcript in CIS containing parenchyma is most likely explained by the replacement of spermatogenesis by CIS.

We have shown that VASA is an informative marker for normal germ cells and germ cell tumors that retain 
germ cell features; ie, classic seminoma/dysgerminoma and spermatocytic seminomas. Currently, immunohistochemical staining for GCAP/PLAP is frequently used to confirm the histopathologic diagnosis of classic seminoma/dysgerminoma, either in metastases or in cases in which the primary tumor exhibits histologic overlap with other tumor types (ie, lympho$\mathrm{ma}$ ). Although it is a fairly sensitive marker for classic seminoma/dysgerminoma, GCAP/PLAP is not expressed in spermatocytic seminoma (Dekker et al, 1992). The diagnostic usefulness of GCAP/PLAP is further limited by lack of specificity, because it is frequently expressed in nongerm cell tumors such as ovarian carcinoma (in as many as half of ovarian papillary serous carcinomas) (Nakopoulou et al, 1995) and other neoplasms, particularly those of gastrointestinal origin (Hamilton-Dutoit et al, 1990). In addition, GCAP/PLAP is expressed in several normal tissues (Hamilton-Dutoit et al, 1990). In contrast, the highly specific expression of VASA in normal germ cells and in specific subtypes of germ cell tumors (our study) suggests that VASA is likely to be a useful diagnostic marker with greater specificity than GCAP/PLAP.

In conclusion, our results on the expression of VASA and the presence of the corresponding protein confirm the germ cell lineage origin of gonadoblastoma/ CIS, dysgerminoma/classic seminoma, and spermatocytic seminoma. The data support the model that TGCT are derived from an early germ cell, and that spermatocytic seminomas mimic the developmental stage of spermatocytes. The lack of VASA, both mRNA and protein in nonseminomas and derived cell lines is in accordance with differentiation toward embryonal and extraembryonic tissue and concomitant loss of their germ cell-specific characteristics.

\section{Materials and Methods}

\section{Collection of Tissue Samples}

Freshly obtained tumor samples were collected in collaboration with urologists and pathologists in the southwestern part of The Netherlands. Immediately after removal, portions of the tumor were snap-frozen or fixed overnight in $10 \%$ buffered formalin and embedded in paraffin. Standard procedures were followed for tumor diagnosis, according to WHO classification (Mostofi and Sesterhenn 1998).

A total of 2 dysgerminomas, 2 gonadoblastomas, 3 mixed gonadoblastoma/dysgerminoma, 5 normal testes (containing spermatogenesis), 3 Leydig cell tumors, 3 primary testicular lymphomas, 14 samples containing $\mathrm{CIS}$ and/or Sertoli-only tubules adjacent to tumor or normal testicular parenchyma, 13 seminomas, 12 nonseminomas, and 4 spermatocytic seminomas (from 3 patients; one patient had a bilateral tumor) were analyzed for the presence of the VASA protein. In addition, one peripheral blood lymphocyte sample, normal testes $(n=2)$, a series of samples containing $15 \% \mathrm{CIS}(n=2), 50 \% \mathrm{CIS}(n=1), 65 \% \mathrm{CIS}$ $(n=1)$, and $80 \%$ CIS $(n=2)$ tubules, 5 classic seminomas, 6 nonseminomas (2 embryonal carcino- mas, 2 yolk sac tumors, and 2 teratomas), and the 4 spermatocytic seminomas (see above) were analyzed for VASA transcript levels using semiquantitative RT-PCR.

\section{Immunohistochemistry}

Tissue sections $3 \mu \mathrm{m}$ thick of formalin-fixed paraffinembedded samples were mounted on APES (3aminopropyl-triethoxysilane)-coated glass slides and used for simultaneous incubation with antibodies directed against the VASA protein and GCAP/PLAP. Slides were pretreated for antigen-retrieval (Shi et al, 1991), using $10 \mathrm{~mm}$ citrate buffer, $\mathrm{pH}$ 7.0. VASA immunohistochemical stainings were performed overnight at $4^{\circ} \mathrm{C}$ using a rabbit polyclonal antibody against the human VASA protein, as previously described (Castrillon et al, 2000), at 1:1500 dilution. Visualization was performed by incubation with the second antibody biotinylated swine-anti-rabbit (DAKO A/S, Glostrup, Denmark; cat. no. E0431) at 1:200 dilution followed by incubation with avidin-biotin-alkaline phosphatase complex (DAKO A/S; cat. no. K0391) using Fast-blue BB (Sigma, St. Louis, Missouri) as chromogen. For immunohistochemical staining of GCAP/PLAP, a monoclonal antibody (Novocastra, Newcastle, United Kingdom; NCL-PLAP-8A9) was used at 1:10 dilution. The primary antibody was detected using goat-anti-mouse-HRP (DAKO; cat. no. P0447) at 1:100 and mouse-anti-peroxidase-PO (Sigma; cat. no. P3039) 1:100 dilution with AEC (= 3-amino-9-ethyl-carbazole) as chromogen. The staining results were found to be sensitive to fixation. This was demonstrated by an overall weaker staining intensity in the center of the tissue block than at the edges of all samples. Processing tissue as thin tissue slices, allowing optimal fixation, avoided this weaker staining in the center of the block.

\section{Semiquantitative RT-PCR}

Total RNA was isolated from fresh frozen tissue sections. Adjacent sections were stained with hematoxylin and eosin as histologic control. Standard procedures were used for RNA isolation with TRIzol reagent (InVitrogen, Carlsbad, California) from five 30- $\mu \mathrm{m}-$ thick sections per tumor. Cell-line RNA was isolated similarly. First-strand cDNA was synthesized from 4 $\mu \mathrm{g}$ total RNA with SuperScript-II reverse transcriptase following the manufacturer's instructions (InVitrogen).

Relative quantification of the VASA-transcript levels was performed by duplex PCR with VASA specific primers (primer sequences: 5' AAG AGA GGC TAT CGA GAT GGA 3' and 5' CGT TCA CTT CCA CTG CCA CTT CTG 3') compared with HPRT (primer sequences: 5' CGT GGG GTC CTT TTC ACC AGC AAG $3^{\prime}$ and 5' AAT TAT GGA CAG GAC TGA ACG TC 3'; Jolly et al, 1983), resulting in amplification products of $238 \mathrm{bp}$ and $387 \mathrm{bp}$, respectively. The expression level of HPRT is constant in most tissues, including the testis, and can therefore serve as an internal RT-PCR standard (Pannetier et al, 1993). 
PCR reactions were performed in a Peltier Thermal Cycler 200 machine (MJ Research, Watertown, Massachusetts) under the following conditions: 3 minutes at $94^{\circ} \mathrm{C}$, then 30 seconds at $94^{\circ} \mathrm{C}, 30$ seconds at $56^{\circ} \mathrm{C}$, and 30 seconds at $72^{\circ} \mathrm{C}$ ( 26 cycles), 2 minutes at $72^{\circ} \mathrm{C}$ (final extension step) in $60 \mu \mathrm{l}$ reaction volume ( $1 \mu \mathrm{l} \mathrm{cDNA}$ (the equivalent of $250 \mathrm{ng} \mathrm{RNA}$ ), $50 \mathrm{~mm} \mathrm{KCl}$, $10 \mathrm{~mm}$ Tris (pH 9.0), $0.1 \%$ Triton X-100, $1.5 \mathrm{~mm} \mathrm{MgCl}{ }_{2}$, $0.2 \mu \mathrm{M}$ dGTP, dTTP, dCTP, and dATP, $0.25 \mu \mathrm{l} \alpha^{32} \mathrm{P}-$ dATP $(0.0925 \mathrm{MBq}), 0.2 \mu \mathrm{M}$ of each primer, $0.5 \mathrm{U}$ TaqPolymerase (QIAGEN, Hilden, Germany). After 20, $21,22,23$, and 24 cycles of amplification, $10 \mu \mathrm{l}$ samples were taken for analysis, to which $2 \mu$ loading buffer (type 2; Sambrook et al, 1989) was added. Four microliters of each sample was loaded on a $4 \%$ native polyacrylamide gel and run for $21 / 2$ hours $(400 \mathrm{~V}, 13$ $\mathrm{mA}, 8 \mathrm{~W}$ ), and then the gel was dried under vacuum. Radioactive signals were quantified with the Storm 820 Phosphor Imager System (Molecular Dynamics, Sunnyvale, California), using Image-quant software.

\section{References}

Adami HO, Bergström R, Möhner M, Zatonski W, Storm H, Ekbom A, Tretli S, Teppo L, Ziegler H, Rahu M, Gurevicius R, and Stengrevics A (1994). Testicular cancer in nine northern European countries. Int J Cancer 59:33-38.

Burke AP and Mostofi FK (1993). Spermatocytic seminoma: A clinicopathologic study of 79 cases. J Urol Pathol 1:21-32.

Castrillon DH, Quade BJ, Wang TY, Quigley C, and Crum CP (2000). The human VASA gene is specifically expressed in the germ cell lineage. Proc Natl Acad Sci USA 97:9585-9590.

Cummings OW, Ulbright TM, Eble JN, and Roth LM (1994). Spermatocytic seminoma: An immunohistochemical study. Hum Pathol 25:54-59.

Dekker I, Rozeboom T, Delemarre J, Dam A, and Oosterhuis JW (1992). Placental-like alkaline phosphatase and DNA flow cytometry in spermatocytic seminoma. Cancer 69:993-996.

Eble JN (1994). Spermatocytic seminoma. Hum Pathol 25: 1035-1042.

Forbes A and Lehmann R (1998). Nanos and Pumilio have critical roles in the development and function of Drosophila germline stem cells. Development 125:679-90.

Gavis ER, Curtis D, and Lehmann R (1996). Identification of cis-acting sequences that control nanos RNA localization. Dev Biol 176:36-50.

Ghabrial A and Schupbach T (1999). Activation of a meiotic checkpoint regulates translation of Gurken during Drosophila oogenesis. Nat Cell Biol 1:354-7.

Gonzalez-Reyes A, Elliott H and St Johnston D (1995). Polarization of both major body axes in Drosophila by gurken-torpedo signalling. Nature 375:654-8.

Hamilton-Dutoit SJ, Lou H, and Pallesen G (1990). The expression of placental alkaline phosphatase (PLAP) and PLAP-like enzymes in normal and neoplastic human tissues: An immunohistological survey using monoclonal antibodies. APMIS 98:797-811.

Hay B, Jan LY, and Jan YN (1988). A protein component of Drosophila polar granules is encoded by Vasa and has extensive sequence similarity to ATP-dependent helicases. Cell 55:577-87.

Jolly DJ, Okayama H, Berg P, Esty AC, Filpula D, Bohlen P, Johnson GG, Shively JE, Hunkapillar T, and Friedmann $T$ (1983). Isolation and characterization of a full-length expressible cDNA for human hypoxanthine phosphoribosyl transferase. Proc Natl Acad Sci USA 80:477-81.

Jørgensen N, Muller J, Jaubert F, Clausen OP, and Skakkebaek NE (1997). Heterogeneity of gonadoblastoma germ cells: Similarities with immature germ cells, spermatogonia and testicular carcinoma in situ cells. Histopathology 30:17786.

Jørgensen N, Rajpert-De Meyts E, Graem N, Müller J, Giwercman A, and Skakkebæk NE (1995). Expression of immunohistochemical markers for testicular carcinoma in situ by normal fetal germ cells. Lab Invest 72:223-231.

Kobayashi S, Yamada M, Asaoka M, and Kitamura T (1996). Essential role of the posterior morphogen nanos for germline development in Drosophila. Nature 380:708-11.

Lasko PF and Ashburner M (1988). The product of the Drosophila gene Vasa is very similar to eukaryotic initiation factor-4A. Nature 335:611-7.

Looijenga LHJ, Gillis AJM, Van Gurp RJHLM, Verkerk AJMH, and Oosterhuis JW (1997). X inactivation in human testicular tumors: XIST expression and androgen receptor methylation status. Am J Pathol 151:581-590.

Looijenga LHJ, Olie RA, Van der Gaag I, van Sluijs FJ, Matoska J, Ploem-Zaaijer J, Knepfle C, and Oosterhuis JW (1994). Seminomas of the canine testis; counterpart of spermatocytic seminoma of men? Lab Invest 71:490-496.

Looijenga LHJ and Oosterhuis JW (1999). Pathogenesis of testicular germ cell tumors. Rev of Reproduction 4:90-100.

Møller H (1989). Decreased testicular cancer risk in men born in wartime. J Natl Cancer Inst 81:1668-9.

Mosselman S, Looijenga LHJ, Gillis AJM, Van Rooijen MA, Kraft HJ, Van Zoelen EJJ, and Oosterhuis JW (1996). Aberrant platelet-derived growth factor $\alpha$-receptor transcript as a diagnostic marker for early human germ cell tumors of the adult testis. Proc Natl Acad Sci USA 93:2884-2888.

Mostofi FK and Sesterhenn IA (1998). Histological typing of testis tumours. Berlin: Springer.

Muller J, Skakkebaek NE, and Parkinson MC (1987). The spermatocytic seminoma: Views on pathogenesis. Int $\mathrm{J}$ Androl 10:147-56.

Nakopoulou L, Janinis J, Giannopoulou I, Lazaris AC, Koureas A, and Zacharoulis D (1995). Immunohistochemical expression of p53 protein and proliferating cell nuclear antigen in hepatocellular carcinoma. Pathol Res Pract 191:120813.

Neuman-Silberberg FS and Schupbach T (1993). The Drosophila dorsoventral patterning gene gurken produces a dorsally localized RNA and encodes a TGF alpha-like protein. Cell 75:165-74.

Oosterhuis JW, Looijenga LHJ, Geurts van Kessel A, and De Jong B (1993). A cytogenetic classification of germ cell tumors, and its biological relevance. Eur Urol 23:6-8.

Pannetier C, Delassus S, Darche S, Saucier C, and Kourilsky P (1993). Quantitative titration of nucleic acids by enzymatic amplification reactions run to saturation. Nucleic Acids Res 21:577-83. 
Pottern ML, Morris Brwn L, and Devesa SS (1998). Epidemiology and pathogenesis of testicular cancer. In: Ernsthoff MS, editor. Testicular and penile cancer. Oxford: Blackwell Science, 2-10.

Rajpert-De Meyts E, and Skakkebæk NE (1994). Expression of the c-kit protein product in carcinoma-in-situ and invasive testicular germ cell tumours. Int J Androl 17:85-92.

Raz E (2000). The function and regulation of Vasa-like genes in germ-cell development. Genome Biol: 1-6.

Roelofs H, Manes T, Millan JL, Oosterhuis JW, and Looijenga LHJ (1999). Heterogeneity in alkaline phosphatase isozyme expression in human testicular germ cell tumors: An enzyme-/immunohistochemical and molecular analysis. J Pathol 189:236-244.

Romanenko AM and Persidskii YV (1983). Ultrastructure and histogenesis of spermatocytic seminoma. Voprosi Onkologii 19:61-66.

Rosai J, Khodadoust K, and Silber I (1969). Spermatocytic seminoma. Cancer 24:103-116.

Rosenberg C, Mostert MC, Bakker Schut T, Van de Pol M, Van Echten-Arends J, De Jong B, Raap T, Tanke H, Oosterhuis JW, and Looijenga LHJ (1998). Chromosomal constitution of human spermatocytic seminomas: Comparative genomic hybridization supported by conventional and interphase cytogenetics. Genes Chromosom Cancer 23:286291.

Roth S, Neuman-Silberberg FS, Barcelo G, and Schupbach T (1995). Cornichon and the EGF receptor signaling process are necessary for both anterior-posterior and dorsal-ventral pattern formation in Drosophila. Cell 81:967-78.

Sambrook J, Frisch EF, and Maniatis T (1989). Molecular cloning: A laboratory manual. New York: Cold Spring Harbor Laboratory Press.

Scully RE (1970). Gonadoblastoma: A review of 74 cases. Cancer 25:1340-1356.

Shi SR, Key ME, and Kalra KL (1991). Antigen retrieval in formalin-fixed, paraffin-embedded tissues: An enhancement method for immunohistochemical staining based on microwave oven heating of tissue sections. J Histochem Cytochem $39: 741-8$.
Skakkebæk NE (1972). Possible carcinoma-in-situ of the testis. Lancet 516-517.

Stoop H, Van Gurp RHJ, LM, De Krijger R, Geurts van Kessel A, Koberle B, Oosterhuis JW, and Looijenga LHJ (2001). Reactivity of germ cell maturation stage-specific markers in spermatocytic seminoma: Diagnostic and etiological implications. Lab Invest 81:919-928.

Styhler S, Nakamura A, Swan A, Suter B, and Lasko P (1998). Vasa is required for Gurken accumulation in the oocyte, and is involved in oocyte differentiation and germline cyst development. Development 125:1569-78.

Swerdlow AJ (1993). The epidemiology of testicular cancer. Eur Urol 23:35-38.

Talerman A (1974). Spermatocytic seminoma. J Urol 112: 212-6.

Talerman A (1980). Spermatocytic seminoma. Cancer 45: 2169-2176.

Talerman A, Fu YS, and Okagaki T (1984). Spermatocytic seminoma: Ultrastructural and microspectrophotometric observations. Lab Invest 51(3):343-349.

Tanaka SS, Toyooka Y, Akasu R, Katoh-Fukui Y, Nakahara Y, Suzuki R, Yokoyama M, and Noce T (2000). The mouse homolog of Drosophila Vasa is required for the development of male germ cells. Genes Dev 14:841-53.

Tomancak P, Guichet A, Zavorszky P, and Ephrussi A (1998). Oocyte polarity depends on regulation of gurken by Vasa. Development 125:1723-32.

Toyooka Y, Tsunekawa N, Takahashi Y, Matsui Y, Satoh M, and Noce T (2000). Expression and intracellular localization of mouse Vasa-homologue protein during germ cell development. Mech Dev 93:139-49. 